\title{
Remote Administration of the MDS-UPDRS in the Time of COVID-19 and Beyond
}

\author{
Ruth B. Schneider ${ }^{\mathrm{a}, \mathrm{b}, *}$, Taylor L. Myers ${ }^{\mathrm{b}}$, Christopher G. Tarolli ${ }^{\mathrm{a}, \mathrm{b}}$, Katherine Amodeo $^{\mathrm{a}}$, \\ Jamie L. Adams ${ }^{\mathrm{a}, \mathrm{b}}$, Stella Jensen-Roberts ${ }^{\mathrm{b}}$ and E. Ray Dorsey ${ }^{\mathrm{a}, \mathrm{b}}$ \\ ${ }^{a}$ Department of Neurology, University of Rochester, Rochester, NY, USA \\ ${ }^{\mathrm{b}}$ Center for Health + Technology, University of Rochester, Rochester, NY, USA
}

Accepted 28 June 2020

Keywords: Parkinson's disease, telemedicine, coronavirus

The COVID-19 pandemic has disrupted clinical research. Recognizing the importance of participant and research personnel safety, funding and regulatory agencies have issued guidance encouraging temporary modifications to research studies including a shift to remote assessments [1-3]. In the midst of the COVID-19 pandemic, the appeal of conducting remote research visits for individuals with Parkinson's disease (PD) is clear.

Operations for virtual PD research studies [4, 5], have been able to continue seamlessly. In contrast, in-person research studies have had to contend with missed or incomplete visits. In this personal viewpoint, we offer our perspective on remote Movement Disorder Society - Unified Parkinson's Disease Rating Scale (MDS-UPDRS) motor assessment [6], for those considering or in the process of transitioning to remote video-based visits.

The feasibility of conducting a modified version of the MDS-UPDRS motor, without assessment of rigidity or postural stability, has been previously

${ }^{*}$ Correspondence to: Ruth B. Schneider, MD, 265 Crittenden Blvd, Box MIND, Rochester, NY 14642, USA. Tel.: +1 585273 1856; E-mail: Ruth_schneider@urmc.rochester.edu. demonstrated [8-10]; however, it has not been adequately validated against in-person assessment. A secondary analysis of clinical trial data (CALM-PD), which compared a modified Unified Parkinson Disease Rating Scale (UPDRS) motor to the standard UPDRS motor, concluded that the modified version would be cross-sectionally and longitudinally reliable [11]. Direct comparison of in-home, video-based versus in-person administration of the modified UPDRS motor demonstrated moderate overall agreement [8]. In a small study that compared in-person and videobased modified MDS-UPDRS motor assessment, median difference in scores was 3.0 (IQR 1.5-9.0) [12]. Of concern, lower extremity tremor could not be assessed in 10/11 participants. In a recently completed study embedded within a phase 3 clinical trial, 38 participants underwent remote assessment within 4 weeks of in-person assessment [13]. The correlation between the remote and in-person MDS-UPDRS motor was moderate (ICC $=0.51$ ), with lower correlations likely driven by completion by different examiners. Critically, no means for direct comparison of remote and in-person MDS-UDPRS motor scores exists, making interpretation of longitudinal data problematic [7]. The inability to assess rigidity 
and postural instability impedes such direct comparison and complete phenotypic characterization. Efforts are underway to validate the modified MDSUPDRS motor [4].

Collectively, the authors have conducted hundreds of remote MDS-UPDRS motor assessments of individuals at-risk for and with PD of different stages of disease. We can confidently speak to the feasibility and safety of conducting remote assessments. We take precautions to minimize the risk of falls, including requesting participants walk with their assistive device (when applicable) and deferring gait assessment when prudent. We collect the participant's location at the time of the visit in case of emergency. Over two years, we conducted over 550 remote visits with $\mathrm{PD}$ participants across three separate research studies $[4,5,14]$. We had one fall, which occurred outside administration of the MDS-UPDRS in a participant who experienced falls on a daily basis and have never contacted emergency services. Excluding rigidity and postural instability items, we have been able to rate $98.3 \%(15,179 / 15,444)$ of items with assessment of toe tapping, lower extremity rest tremor, and leg agility most commonly missed. Remote MDS-UPDRS assessment is safe and feasible.

However, several factors can affect the accuracy of remote assessment. Environmental factors (lighting, background, space) can reduce or prohibit assessment of certain elements. With in-person visits, examiners can easily visualize the entire body throughout the visit, which enables accurate assessment of global bradykinesia and rest tremor. To achieve this during a remote visit, the camera should be approximately 6-8 feet from the participant. However, this is often not possible. Moreover, evaluation at this distance may impede assessment of hypomimia, postural tremor and action tremor. Repositioning of the camera and participant should be anticipated. In our opinion, remote MDS-UPDRS assessment likely underrates global bradykinesia and rest tremor. Additionally, space may not allow for adequate assessment of gait and freezing of gait. Technical factors (internet speed, quality of connection and camera) can similarly limit assessment. Laptops, tablets, and smartphones can be easily repositioned whereas the inability to maneuver desktop cameras may impede assessment of lower extremities. Subtle bradykinesia or tremor can be difficult to appreciate remotely, even under ideal conditions. A poor connection can make assessment more challenging, but may be helped by closer proximity to the internet router.
Participant factors (age, access/familiarity with technology, disease stage, cognitive status) can present additional challenges. In our experience, remote visits can be successfully conducted among older individuals and those with substantial disability [15] and may be even more valuable among this group given their travel-related challenges and higher risk for worse outcomes with COVID-19 [16]. To improve participant comfort and the likelihood of success, adequate preparation is critical. In test visits, coordinators can explain how to connect, determine the ideal set-up, and review the evaluations. The inclusion of care partners in visits can also help mitigate some of these issues and their participation should be encouraged for participants with more advanced disease. Lastly, investigator factors (familiarity with the technology and with remote examination) can impact assessment. Investigators, even those well-experienced, should be trained on remote assessment by viewing sample recordings of remote MDS-UPDRS examinations and shadowing a live visit. To assist researchers, we have made the protocol and model consent form for one of our virtual studies (AT-HOME PD) freely available (https://www.athomepd.org/professionals).

Clinical researchers must find a way to safely continue important research during the COVID19 pandemic. While remote MDS-UPDRS motor assessment presents some challenges, many of these can be mitigated, and in our opinion, remote assessment is appropriate for many on-going research studies. However, the specifics of the research should guide this decision; we would not recommend remote MDS-UPDRS motor assessment for a treatment trial in which it is the primary outcome measure. One viable alternative is the remote assessment of patientreported outcomes. Digital tools, such as wearable sensors, which can provide objective, real-world data have enormous potential as surrogate outcome measures and may ultimately supplant remote MDSUPDRS assessment. More work is needed to validate remote MDS-UPDRS motor assessment; however, we anticipate that one long-term effect of the COVID19 pandemic will be that more researchers will embrace the use of video-based visits and digital tools.

\section{ACKNOWLEDGMENTS}

This commentary is based on research funded by the National Institutes of Health and Michael J. Fox Foundation for Parkinson's research. 


\section{CONFLICT OF INTEREST}

The authors have no conflicts of interest to report.

\section{FINANCIAL DISCLOSURES (PRIOR 12 MONTHS)}

Ruth B. Schneider is employed by the University of Rochester and has received grants and research support from National Institutes of Health, Michael J. Fox Foundation for Parkinson's Research, Biohaven Pharmaceuticals, Acadia Pharmaceuticals, and the CHDI Foundation.

Taylor L. Myers is employed by the University of Rochester and has no disclosures.

Christopher G. Tarolli is employed by the University of Rochester and has received honoraria from the American Academy of Neurology and the Davis Phinney Foundation. He has received grants and research support from National Institutes of Health, Michael J. Fox Foundation for Parkinson's Research, American Academy of Neurology Institute, Biosensics, and Greater Rochester Health Foundation.

Katherine Amodeo is employed by the University of Rochester and has received grants and research support from the Michael J Fox Edmund J. Safra Fellowship in Movement Disorders from July 2017-July 2019. She is an investigator and/or medical monitor for clinical trials supported by Genentech Roche Ltd, EIP Pharma Inc, Michael J. Fox foundation for Parkinson's Research, National Institutes of Health, Acadia Pharmaceuticals, and Biogene.

Jamie L. Adams is employed by the University of Rochester and has consulted for VisualDx. She has received honoraria from Huntington Study Group and grants and research support from National Institutes of Health, Michael J. Fox Foundation for Parkinson's Research, Biogen, Safra Foundation, and Empire Clinical Research Investigator Program.

Stella Jensen-Roberts is employed by the University of Rochester and has no disclosures.

Earl R. Dorsey is employed by the University of Rochester and has ownership Interests in Grand Rounds, an online second opinion service. He has consulted for 23 and Me, Abbott, Abbvie, Amwell, Biogen, Clintrex, CuraSen, DeciBio, Denali Therapeutics, GlaxoSmithKline, Grand Rounds, Huntington Study Group, Informa Pharma Consulting, medical-legal services, Mednick Associates, Medopad, Olson Research Group, Origent Data Sciences, Inc., Pear Therapeutics, Prilenia, Roche,
Sanofi, Shire, Spark Therapeutics, Sunovion Pharmaceuticals, Voyager Therapeutics, and ZS Consulting. He has received honoraria from Alzheimer's Drug Discovery Foundation, American Academy of Neurology, American Neurological Association, California Pacific Medical Center, Excellus BlueCross BlueShield, Food and Drug Administration, MCM Education, Michael J. Fox Foundation, Stanford University, UC Irivine, and University of Michigan. He has received grants and research support from Abbvie, Acadia Pharmaceuticals, AMC Health, BioSensics, Burroughs Wellcome Fund, Greater Rochester Health Foundation, Huntington Study Group, Michael J. Fox Foundation, National Institutes of Health, Nuredis, Inc., Patient-Centered Outcomes Research Institute, Pfizer, Photopharmics, Roche, and Safra Foundation.

\section{REFERENCES}

[1] Guidance for NIH-funded Clinical Trials and Human Subjects Studies Affected by COVID-19, National Institutes of Health, https://grants.nih.gov/grants/guide/noticefiles/NOT-OD-20-087.html, March 16, 2020, Accessed May 1, 2020.

[2] U.S. Food and Drug Administration, FDA Guidance on Conduct of Clinical Trials of Medical Products during COVID-19 Public Health Emergency, https://www. fda.gov/media/136238/download, March 2020, Accessed May 1, 2020.

[3] Guidance on the Management of CLinical Trials during the COVID-19 (Coronavirus) Pandemic, https://ec.europa. eu/health/sites/health/files/files/eudralex/vol-10/guidancecl inicaltrials_covid19_en.pdf, April 28, 2020, Accessed May $1,2020$.

[4] Myers T SR, Anthwal S, Kayson E, Omberg L, Tarolli C, Macklin E, Daeschler M, Dorsey ER, Mangravite L, Schwarzchild M, Simuni T (2019) Assessing tele-health outcomes in multiyear extensions of Parkinson's disease trials (AT-HOME PD): Initiation of a long-term observational study, 5th World Parkinson Congress, Kyoto, Japan: World Parkinson Coalition.

[5] Myers T SR, Jensen-Roberts S, Rowbotham HM, Luff MK, Chanoff E, Amodeo K, Sharma S, Alcalay RN, Cannon P, Dorsey ER, Holloway R, (2020) Recruitment of a virtual nationwide cohort of LRRK2 G2019S carriers, American Academy of Neurology Annual Meeting, Presented Virtually.

[6] Goetz CG, Tilley BC, Shaftman SR, Stebbins GT, Fahn S, Martinez-Martin P, Poewe W, Sampaio C, Stern MB, Dodel R, Dubois B, Holloway R, Jankovic J, Kulisevsky J, Lang AE, Lees A, Leurgans S, LeWitt PA, Nyenhuis D, Olanow CW, Rascol O, Schrag A, Teresi JA, van Hilten JJ, LaPelle N, Movement Disorder Society UPDRS Revision Task Force (2008) Movement Disorder Society-sponsored revision of the Unified Parkinson's Disease Rating Scale (MDS-UPDRS): Scale presentation and clinimetric testing results. Mov Disord 23, 2129-2170. 
[7] Goetz CG, Stebbins GT, Luo S (2020) Movement Disorder Society-Unified Parkinson's Disease Rating Scale use in the Covid-19 era. Mov Disord 35, 911.

[8] Cubo E, Gabriel-Galan JM, Martinez JS, Alcubilla CR, Yang C, Arconada OF, Perez NM (2012) Comparison of office-based versus home Web-based clinical assessments for Parkinson's disease. Mov Disord 27, 308-311.

[9] Dorsey ER, Wagner JD, Bull MT, Rizzieri A, Grischkan J, Achey MA, Sherer T, Chowdhury S, Meunier C, Cappelletti L, Rocker C, Richard IH, Schwarz H, Kang G, Ahmad SH, Biemiller RA, Biglan KM (2015) Feasibility of virtual research visits in Fox Trial Finder. J Parkinsons Dis $\mathbf{5}$, 505-515.

[10] Dorsey ER, Deuel LM, Voss TS, Finnigan K, George BP, Eason S, Miller D, Reminick JI, Appler A, Polanowicz J, Viti L, Smith S, Joseph A, Biglan KM (2010) Increasing access to specialty care: A pilot, randomized controlled trial of telemedicine for Parkinson's disease. Mov Disord 25, 1652-1659.

[11] Abdolahi A, Scoglio N, Killoran A, Dorsey ER, Biglan KM (2013) Potential reliability and validity of a modified version of the Unified Parkinson's Disease Rating Scale that could be administered remotely. Parkinsonism Relat Disord 19, 218-221.

[12] Stillerova T, Liddle J, Gustafsson L, Lamont R, Silburn P (2016) Remotely assessing symptoms of Parkinson's disease using videoconferencing: A feasibility study. Neurol Res Int 2016, 4802570.

[13] Tarolli CG AK, Bull MT, Goldenthal S, O'Brien M, Simuni T, Zimmerman G, Biglan KM, Dorsey ER, (2020) Virtual research visits in individuals with Parkinson disease enrolled in a clinical trial: REACT-PD Study, American Academy of Neurology Annual Meeting, Presented Virtually.

[14] Schneider RB MT, Daeschler M, Tarolli C, Adams J, Barbano R, Riley L, Amondikar N, Auinger P, Diaz M, Dorsey ER, Marras C, Tanner C (2020) Validation of Fox Insight cohort via virtual research visits, American Academy of Neurology Annual Meeting, Presented Virtually.

[15] Tarolli CG, Zimmerman GA, Goldenthal S, Feldman B, Berk S, Siddiqi B, Kopil CM, Chowdhury S, Biglan KM, Dorsey ER, Adams JL (2020) Video research visits for atypical parkinsonian syndromes among Fox Trial Finder participants. Neurol Clin Pract 10, 7-14.

[16] Zhou F, Yu T, Du R, Fan G, Liu Y, Liu Z, Xiang J, Wang Y, Song B, Gu X, Guan L, Wei Y, Li H, Wu X, Xu J, Tu S, Zhang Y, Chen H, Cao B (2020) Clinical course and risk factors for mortality of adult inpatients with COVID-19 in Wuhan, China: A retrospective cohort study. Lancet 395, 1054-1062. 